\title{
Penggunaan Sensor ACS712 dan Sensor Tegangan untuk Pengukuran Jatuh Tegangan Tiga Fasa Berbasis Mikrokontroler dan Modul GSM shield
}

\author{
Muhammad Taif ${ }^{1}$, M. Yunus Hi Abbas ${ }^{1,2}$, Moh.Jamil ${ }^{3}$ \\ ${ }^{1}$ Program Studi Teknik Elektro \\ ${ }^{3}$ Program Studi Teknik Informatika \\ Fakultas Teknik \\ Universitas Khairun \\ Ternate, Indonesia
}

email: 'taifmuhammad33@gmail.com, ${ }^{2}$ myunus2007@gmail.com, 3iamilkhairun@gmail.com

\begin{abstract}
Abstrak- Jatuh tegangan yang melebihi toleransi dapat mengakibatkan banyak peralatan elektronik yang tidak bisa bekerja secara maksimal bahkan beberapa mengalami kerusakan. Oleh karena itu, penelitian ini merancangan sistem yang dapat mengukur jatuh tegangan tiga fasa yang dapat melaporkan secara waktu nyata. Sistem yang dibangun menggunakan modul Arduino Uno R3, Modul GSM/GPRS Shield SIM900, sensor Tegangan dan sensor Arus ACS712 30A. Hasil pengukuran dari sistem tercatat tegangan dan arus dalam keadan kurang berbeban sampai berbeban fasa $R$ 223, 46 - 211,22 Volt dan Arus fasa R 10, 01 - 19, 79 A fasa S 224, 27 - 214,44 Volt dan Arus fasa $S$ 17, 41-19,48 A serta fasa $T$ 222, 39213,77 Volt dan Arus fasa T 7, 46-11,53 A dengan sistem mengirimkan laporan kepada pengguna dengan rata-rata waktu 10,11 detik.
\end{abstract}

Kata kunci : Arduino Uno R3, GSM/GPRS Shiled SIM900, Sensor Tegangan, Sensor Arus.

\section{PENDAHULUAN}

Perkembangan teknologi berdampak pada pola pikir dan perubahan pada kehidupan manusia mulai dari kebutuhan dasar sampai pada kebutuhan tersier seperti konsumsi penggunaan peralatan elektronik [1[. sekarang dengan mudah di jangkau oleh kalangan masyarakat guna agar memenuhi kebutuhan hidup mereka. Akibat jatuh tegangan yang melebihi toleransi mengakibatkan banyak peralatan elektronik yang tidak bisa bekerja secara maksimal bahkan beberapa mengalami kerusakan [2]-[5].

Oleh karena itu, dirancanglah sebuah sistem yang dapat mengukur jatuh tegangan. Dalam perancangan alat pengukuaran jatuh tegangan tiga fasa berbasis mikrokontroler dan gsm/gprs shield menggunakan modul Arduino Uno R3, Modul GSM/GPRS Shield SIM900, Sensor Tegangan, Sensor Arus ACS712 30A dan LCD 20x4 Karakter.

\section{DASAR TEORI}

\subsection{Catu Daya}

Catu daya adalah rangkain elektronika yang berfungsi untuk memasok daya ke komponen pada perangkat elektronika yang mengubah arus listrik bolak-balik menjadi arus listrik searah. Pada rangkaian catu daya terdapat IC regulator sebagai penstabil tegangan output. Rangkaian regulator tegangan adalah rangkaian pengatur tegangan agar tegangan yang keluar dari rangkaian ini tetap pada satu nilai meskipun masukkannya lebih besar dari nilai yang diinginkan. Pada perancangan ini digunakan LM 7806 dan LM 7812 sebagai regulator tegangan dikarenakan LM 7806 bisa menerima tegangan masukan antara $8 \mathrm{~V}-18 \mathrm{~V}$ tetapi tegangan keluarannya bernilai $6 \mathrm{~V}$ dan 12 Volt yang sesuai dengan tegangan yang dibutuhkan oleh gsm/gprs shield dan mikrokontroler sebagai catu dayanya.

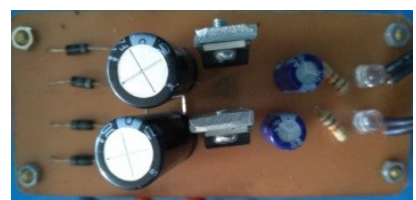

Gambar 1. Catu Daya

\subsection{Sensor Tegangan}

Sensor tegangan mengambil tegangan output dari trafo step down yang kemudian di searahkan menggunakan 4 buah dioda 1buah kapasitor $47 \mu \mathrm{F} 200$ Volt dan 4 buah resistor yang terdiri dari $\mathrm{R} 1=1,5 \mathrm{k} \Omega$ dan $\mathrm{R} 2=200 \mathrm{k} \Omega$. Resistor berfungsi untuk membagi tegangan masukan agar tegangan output sesuai dengan tegangan masukan ADC pada mikrokontroler. Resitor dihubung seri agar nilai tahanannya besar dan bisa mengatasi beban yang besar.

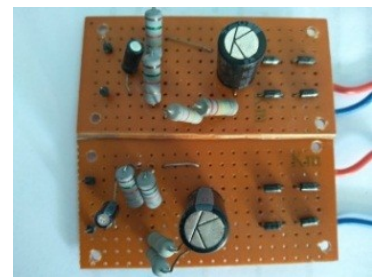

Gambar 2. Sensor Tegangan 


\section{Penggunaan Sensor ACS712 dan Sensor Tegangan untuk Pengukuran Jatuh Tegangan Tiga Fasa Berbasis Mikrokontroler dan Modul GSM shield}

\subsection{Sensor Arus ACS712 30A}

ACS712 merupakan suatu IC terpaket yang mana berguna sebagai sensor arus menggantikan transformator arus yang relatif besar dalam hal ukuran. Pada prinsipnya ACS712 sama dengan sensor efek hall lainnya yaitu dengan memanfaatkan medan magnetik disekitar arus kemudian dikonversi menjadi tegangan yang linier dengan perubahan arus. Nilai variabel dari sensor ini merupakan input untuk mikrokontroler yang kemudian diolah. Keluaran dari sensor ini masih berupa sinyal tegangan $\mathrm{AC}$, agar dapat diolah mikrokontroler maka sinyal tegangan $\mathrm{AC}$ ini disearahkan oleh rangkaian penyearah

\subsection{LCD 20x4 Karakter}

LCD (Liquid Crystal Display) merupakan suatu perangkat elektronika yang telah terkonfigurasi dengan kristal cair dalam gelas plastik atau kaca sehingga mampu memberikan tampilan berupa titik, garis, simbol, huruf, angka ataupun gambar. LCD terbagi menjadi dua macam berdasarkan bentuk tampilannya, yaitu text LCD dan Grapic LCD. Berupa huruf atau angka, sedangkan bentuk tampilan pada Grapic LCD berupa titik, garis dan gambar.

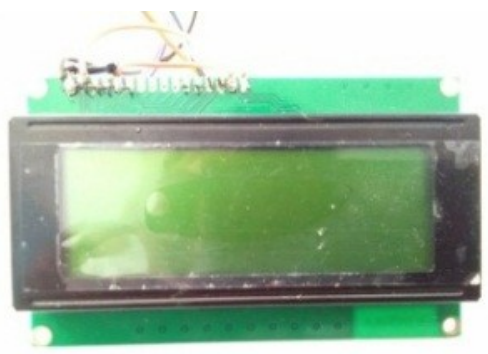

Gambar 3. LCD 20x4 Karakter

\subsection{Arduino Uno R3}

Arduino adalah mikrokontroler singleboard yang dirancang untuk mempermudah penggunanya karena sifatnya yang open source. Piranti ini dapat dimanfaatkan untuk membuat rangkaian elektronik dari yang sederhana hingga yang kompleks. Arduino Uno dilengkapai dengan osilator $16 \mathrm{MHz}$, regulator 5 volt. Pada Arduino Uno terdapat sejumlah pin yaitu 0-13 yang merupakan input dan pin A0-A5 yang merupakan input analog. Arduino Uno dilengkapai dengan konektor USB, konektor catu daya, header ICSP, dan tombol reset, SRAM berukuran 2 $\mathrm{KB}$, flash memory berukuran $32 \mathrm{~KB}$ dan EPROM untuk menyimpan data.

Physical computing adalah sebuah sistem atau perangkat fisik dengan menggunakan software dan hardware yang sifatnya interaktif yaitu dapat menerima rangsangan dari lingkungan dan merespon balik. Physical computing adalah sebuah konsep untuk memahami hubungann antara lingkungan yang sifatnya alaminya adalah analog dengan dunia digital. Arduino dikatakan sebagai sebuah platform dari physical computing yang bersifat open source. Arduino tidak hanya sekedar sebuah alat pengembangan, tertapi ia adalah kombinasi dari hardware, bahasa pemrograman da Integrated Development Environment (IDE) yang canggih. IDE adalah sebuah software yang sangat berperan untuk menulis program mengkompilasi menjadi biner dan mengupload ke dalam memori mikrokontroler. Arduino dikembangkan oleh sebuah tim yang beranggotakan orang-orang dari berbagai belahan dunia. Anggota inti dari tim ini adalah : Massimo Banzi Milano (Italia), David Cuartielles Malmoe (Swedia), Tom Igoe New York (AS), Gianluca Martino Turino (Italia), dan David A. Mellis Boston (AS)

4.

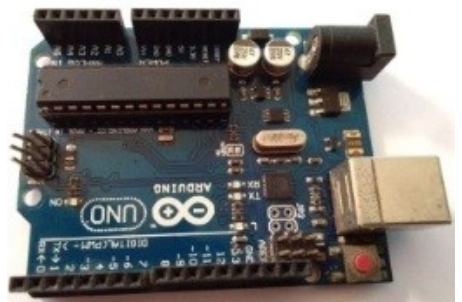

Gambar Uno R3

Arduino

\subsection{GSM/GPRS Shiled SIM900}

GSM (Global System For Mobile Comunication) adalah sistem komunikasi seluler generasi kedua yang menjadi standar global komunikasi nirkabel. Teknologi GSM merupakan standar komunikasi yang lebih banyak diterapkan pada telepon genggaman yang digunakan sebagai alat komunikasi bergerak. GSM meruapakan standar komunikasi yang menyediakan layanan komunikasi dalam bentuk pesan pendek atau SMS (Short Messege Servis). Layanan komunikasi pertukaran pesan pendek antar pengguna jaringan GSM inilah yang paling banyak di gunakan oleh masyarakat. Jangkauan frekuensi standar komunikasi GSM yakni $935-960 \mathrm{MHz}$ untuk transmisi base dan 890-915 untuk transmisi bergerak. Modul GSM shield adalah modul yang berfungsi untuk menerima sms. Pada modul ini terdapat submodul yang merupakan bagian inti dari modul ini yaitu sim900.

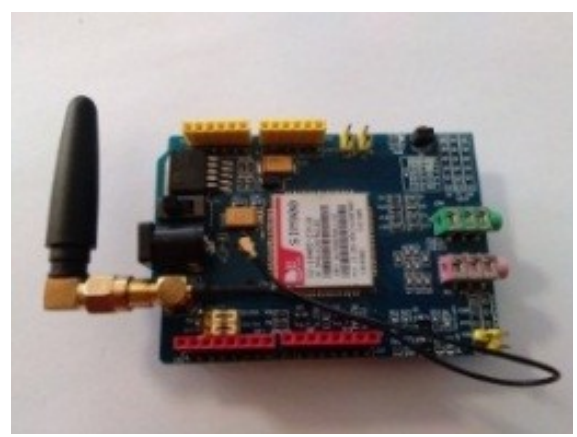

Gambar 5. GSM/GPRS Shield SIM900 


\section{METODOLOGI}

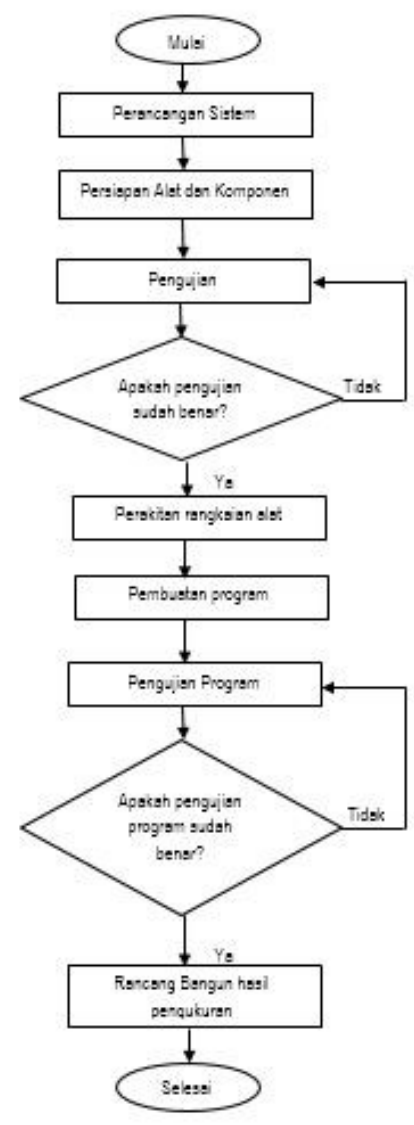

Gambar 6. Diagram Alir Proses Pembuatan Sistem

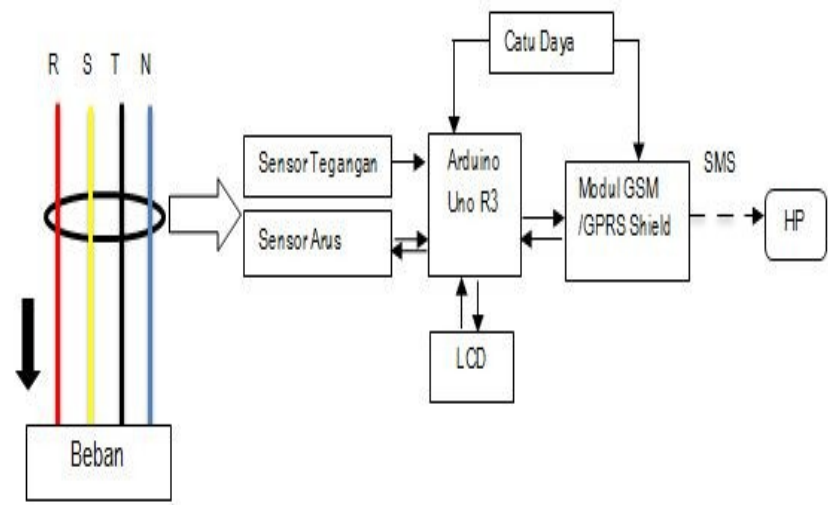

Gambar 7. Diagram Blok Perancangan Sistem

\section{Hasil dan Pembahasan}

\subsection{Perancangan Sistem}

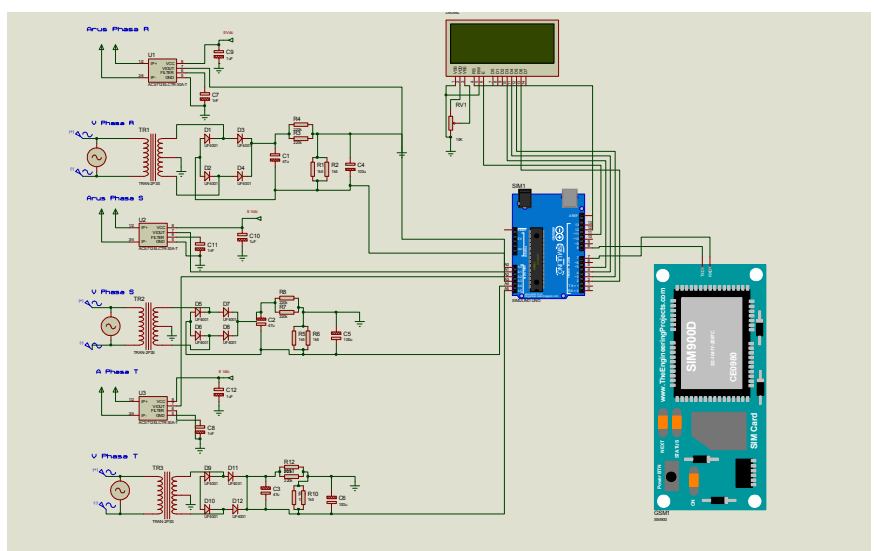

Gambar 8. Rangkaian Keseluruhan Sistem

\subsection{Proses Pembacaan Sensor dan Proses \\ Pengiriman Data Ke Pengguna Handphone}

Ketika tegangan perfasa $\mathrm{R} \mathrm{S} \mathrm{T} \mathrm{yang} \mathrm{terbaca} \mathrm{di}$ bawah 218 Volt maka sensor tegangan dan arus akan mendeteksi nilai besar tegangan dan arus pada saat itu. Output dari keduanya berupa sinyal analog yang akan dikirim ke Arduino Uno melalui pin A0-A5 yang kemudian dari sinyal analog diubah oleh Arduino Uno ke sinyal digital. Sinyal digital ini akan dikirim ke LCD pada pin RS E D4 D5 D6 dan D7 maka LCD akan menampilkan dalam bentuk teks. Arduino Uno R3 akan mengirim sinyal ini pula ke GSM yang terhubung pada pin D8 dan D7 ke pin TX dan RX pada GSM kemudian dari GSM mengirim pesan ke pengguna handphone.

\subsection{Hasil Pengujian Sistem Perancangan}

Keseluruhan

Pengujian dilakukan pada panel gedung Dekanat Lantai I Fakutas Teknik. Pengujian sistem perancangan ini merupakan pengujian untuk mendapatkan data jatuh tegangan dan arus. Data hasil pengukuran akan ditampilkan pada LCD 20x4 dalam bentuk teks dan berupa SMS yang akan dikirim pada pengguna handhphone

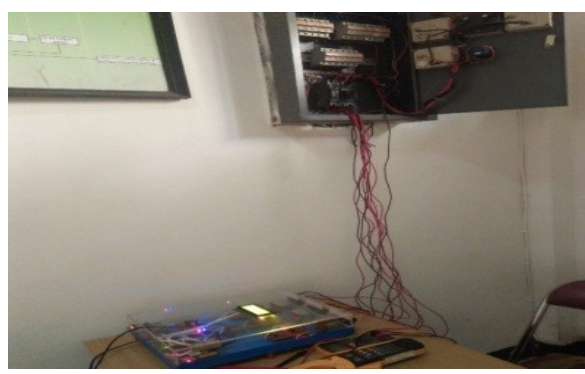

Gambar 9. Pengujian Keseluruhan Sistem 


\section{Penggunaan Sensor ACS712 dan Sensor Tegangan untuk Pengukuran Jatuh Tegangan Tiga Fasa Berbasis Mikrokontroler dan Modul GSM shield}

Tegangan dan Arus R S T tiap fasa yang kurang dari 218 Volt akan di baca oleh sensor tegangan dan sensor arus. Outputnya berupa sinyal analog kemudian di kirim ke pin A0-A5 pada Arduino Uno R3 lalu ditampilkan pada layar LCD seperti gambar 10 setelah itu akan muncul di tampilan LCD seperti gambar 11 di bawah ini.

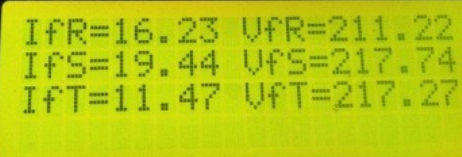

Gambar 10. Tampilan Jatuh Tegangan dan Arus



Gambar 11. Tampilan Jatuh Tegangan

Setelah muncul teks LCD seperti pada gambar 11 maka GSM akan merespon atau menerima sinyal dari Arduino Uno lalu mengirim pesan ke pengguna handphone dengan isi pesan seperti gambar di bawah ini.

\section{! O : : ant anl 14.06 \\ $\leftarrow$ Message Details $\quad$ Reply :}

My GSM TA

JATUH TEGANGAN

TEGANGAN PHASA R $=214.04$

TEGANGAN PHASA $S=217.42$

TEGANGAN PHASA $T=216.67$

ARUS PHASA R $=16.27$

ARUS PHASA $S=19.44$

ARUS PHASA $T=11.49$

Gambar 12. Isi pesan jatuh tegangan dan arus pada handphone

\subsection{Data Hasil Pengukuran}

\subsubsection{Hasil Pengukuran Tegangan}

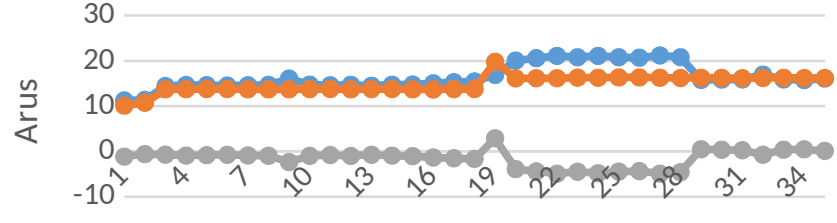

Jumlah Data

\footnotetext{
- Arus R (Clamp On Meter )

- Arus R (Sensor)

- Selisih nilai antara Clamp On meter dan Sensor Arus
}

Gambar 12. Hubungan Tegangan dan Waktu Fasa R

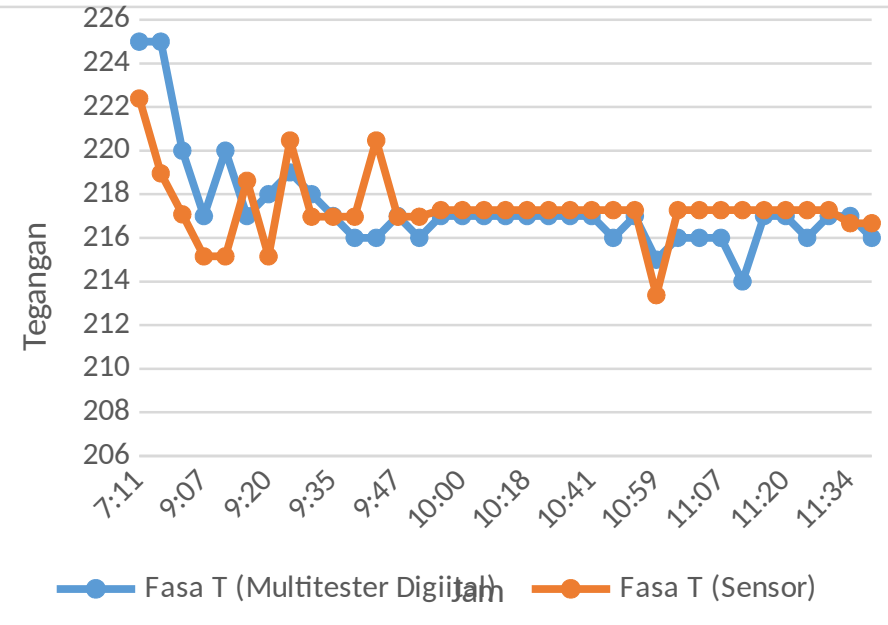

Gambar 13. Selisih Nilai Tegangan Fasa R

Dari gambar 12. dan 13 diatas hasil pengukuran dalam kondisi kurang berbeban dan berbeban dengan menggunakan multitester digital fasa R $224-210$ Volt dan tegangan yang terukur sensor tegangan 223, $46-$ 211, 44 Volt. Selisih nilai dari kedua pengukuran antara $-3,64$ sampai 3,18 .

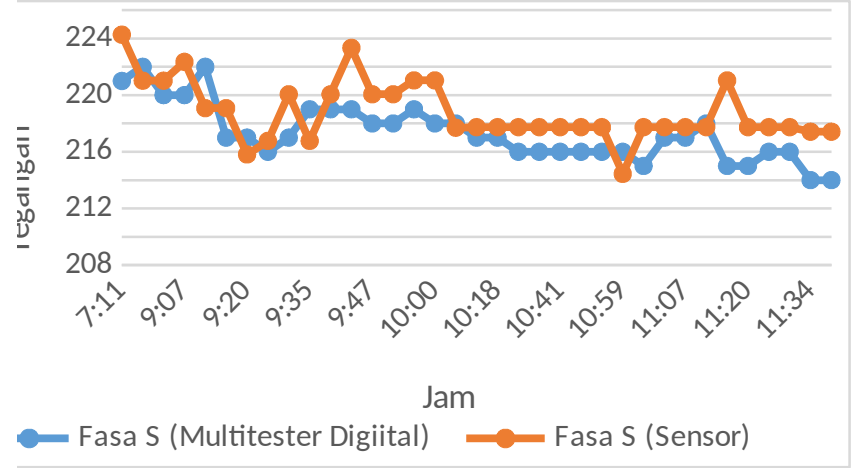

Gambar 14. Hubungan Tegangan dan Waktu Fasa S

Dari gambar 14. diatas pengukuran dalam kondisi kurang berbeban dan berbeban dengan menggunkan multitester digital fasa S 220 - 214 Volt dan tegangan yang terukur dengan sensor tegangan $224-214$ Volt dengan selisih nilai antara -2, 92 sampai 6, 04

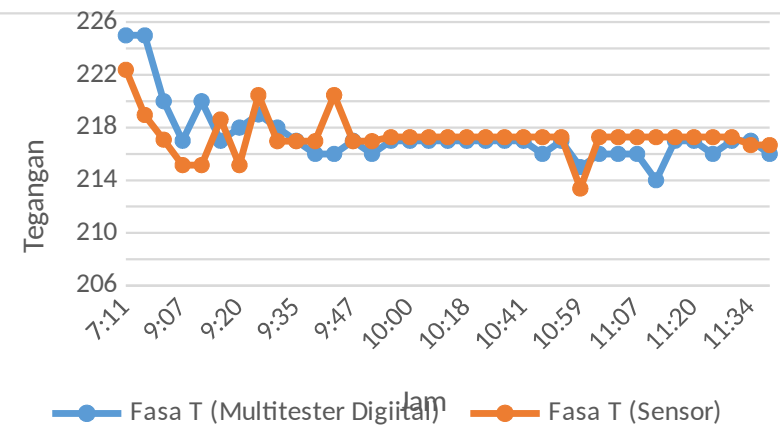

Gambar 15. Hubungan Tegangan dan Waktu Fasa T 


\section{Penggunaan Sensor ACS712 dan Sensor Tegangan untuk Pengukuran Jatuh Tegangan Tiga Fasa Berbasis Mikrokontroler dan Modul GSM shield}

Dari gambar 15 diatas didapatkan hasil pengukuran dengan kondisi kurang berbeban dan berbeban dengan multitester digital tegangan fasa T $225-214$ Volt dan tegangan yang terukur sensor tegangan 222, $39-213,77$ Volt dan selisih dari keduanya antara -6, 04 sampai 4, 47.

\subsubsection{Hasil Pengukuran Arus}

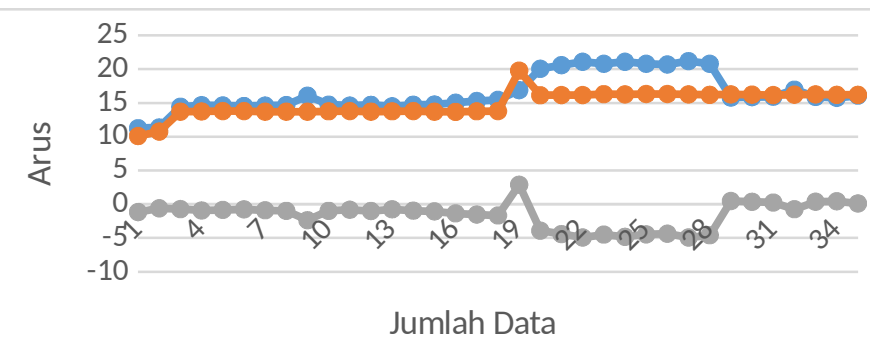

\section{Arus R (Clamp On Meter) \\ Arus R (Sensor) \\ - Selisih nilai antara Clamp On meter dan Sensor Arus}

Gambar 16. Hubungan Arus dan Waktu Fasa R

Dari gambar 16 diatas didapatkan hasil pengukuran dengan kondisi kurang berbeban dan berbeban dengan mengunakan Clamp On Meter arus fasa R 11, 26 - 21, 2 A dan arus yang terukur sensor arus ACS712 10,01 - 19, 79 A dan selisih nilai arus antara -4, 93 sampai 2, 89.

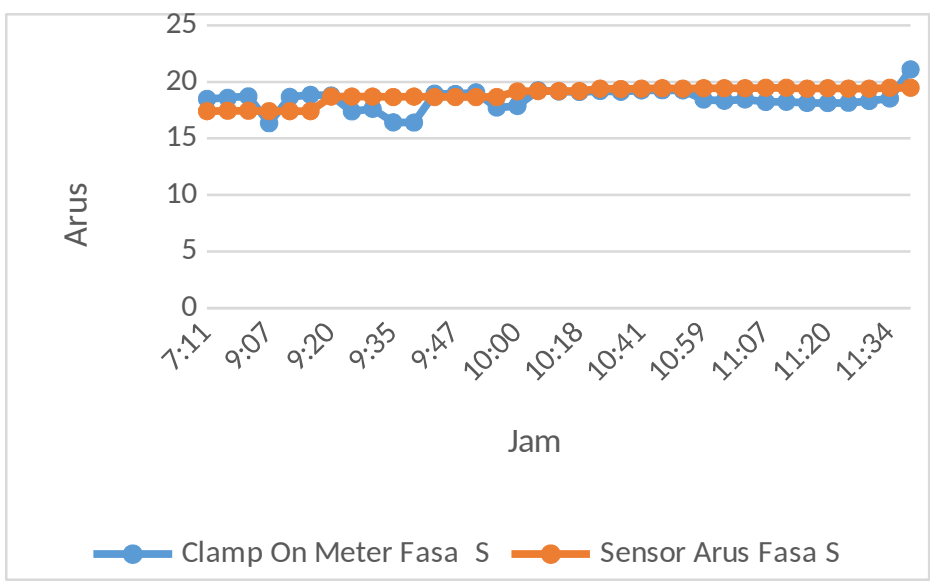

Gambar 17 Hubungan Arus dan Waktu Fasa S

Pada gambar 17 diatas di dapatkan hasil pengukuran dengan kondisi kurang berbeban dan berbeban menggunakan Clamp On Meter arus fasa S 16, 34 - 21, 1 A dan arus yang terukur sensor aru ACS712 19, 48 - 17, 41 A. Selisih nilai antara -1, 62 sampai 2, 24.

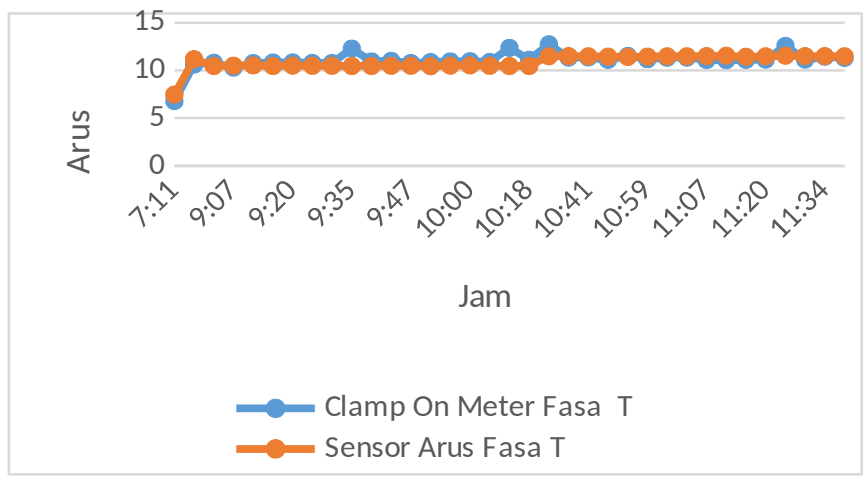

Gambar 18. Hubungan Arus dan Waktu Fasa T

Dari gambar 18 diatas pengukuran dengan kondisi kurang berbeban dan berbaban menggunakan Clamp On Meter arus fasa $\mathrm{T} 11,42-6,78 \mathrm{~A}$ dan arus yang terbaca sensor arus ACS712 7, 46 - 11, 53 A dan selisih nilai antara $-1,91$ sampai 0,68 .

\section{Kesimpulan}

\subsection{Kesimpulan}

Dari proses perancangan sistem sampai pengujian keseluruhan sistem maka dapat disimpulkan bahwa :

1. Dalam perancangan alat pengukuaran jatuh tegangan tiga fasa berbasis mikrokontroler dan Modul GSM/GPRS Shield menggunakan modul Arduino Uno R3, Modul GSM/GPRS Shield SIM900, Sensor Tegangan, Sensor Arus ACS712 30A dan LCD 20x4 Karakter.

2. Tegangan dan Arus perfasa yang terbaca pada setiap sensor akan mengirim sinyal ke Arduino Uno R3 melalui Input Analog A0-A5 lalu di ubah dari sinyal analog ke sinyal digital oleh Arduino Uno R3 dan kemudian di tampilan pada LCD 20x4. Tegangan dan arus yang terukur oleh sensor tegangan dan sensor arus dalam keadan kurang berbeban sampai berbeban fasa R 223, 46 - 211, 22 Volt dan Arus fasa R 10, 01 - 19, 79 A fasa S 224, 27 - 214, 44 Volt dan Arus fasa S 17, 41 - 19, 48 A serta fasa T 222, 39 - 213, 77 Volt dan Arus fasa T 7, 46 - 11, 53 A. Dari data pengujian alat keseluruhan tegangan tiga fasa akan mengalami jatuh tegangan pada saat beban-beban listrik mulai bertambah dan yang terukur oleh sensor tegangan 211, 22 Volt dan sensor arus sebesar 19, 79 A. Ketika terjadi jatuh tegangan maka alat akan mengirim besar tegangan dan arus ke pengguna handphone dengan rata-rata waktu 10, 11 detik 


\subsection{Saran}

Jika alat ini mau di kembangkan maka penulis sarankan agar memperhatikan dan menambah bebrapa hal diantaranya :

1. Seting atau bahasa program sensor arus agar bisa membaca perubhan arus terhadap kondisi beban listrik setiap waktu lebih tepat dan efisien.

2. Perlu menambahkan modul RTC agar data tegangan dan arus yang terbaca waktu secara real time.

3. Perlu menambahkan modul IOT agar data yang terbaca bisa di kontrol lewat online dan offline.

4. Perlu menambahkan Relay agar disaat terjadi jatuh tegangan alat bisa memutuskan koneksi ke beban listrik atau sumber listrik.

\section{DAFTAR PUSTAKA}

[1] Afrizal Fitriandi. 2016. "Rancang Bangun Alat Monitoring Arus Dan Tegangan Berbasis Mikrokontroler Dengan SMS Gateway." 10(2): 88-98.

[2] Dwi W. Suryawan. 2012. "Rancang Bangun Sistem Monitoring Tegangan,Arus Dan Temperatur Pada Sistem Pencatu Daya Listrik DI Teknik Elektro Berbasis Mikrokontroler ATMega 128." 4: 244-50.

[3] Eko Supriyanto. 2015. "Rancang Bangun Alat Pendeteksi Dini Untuk Drop Tegangan Berbasis SMS Gateway." 13: $1-7$.

[4] Lucky Aggazi Subagyo. 2017. "Sistem Monitoring Arus Tidak Seimbang 3 Fasa Berbasis Arduino Uno." 06: 213-21.

[5] Riny Sulistyowati. 2012. "Perancangan Prototype Sistem Kontrol Dan Monitoring Pembatas Daya Listrik Berbasis Mikrokontroler." 16 No.1: 24-32 